\section{Loss of Daxx, a promiscuously interacting protein, results in extensive apoptosis in early mouse development}

\author{
Jennifer S. Michaelson, ${ }^{1,2}$ Debra Bader, ${ }^{1,2}$ \\ Frank Kuo, ${ }^{3}$ Christine Kozak, ${ }^{4}$ and Philip Leder ${ }^{5}$ \\ ${ }^{1}$ Howard Hughes Medical Institute, ${ }^{2}$ Department of Genetics, \\ ${ }^{3}$ Department of Pathology, Brigham and Women's Hospital, \\ Harvard Medical School, Boston, Massachusetts 02115 USA; \\ ${ }^{4}$ National Institutes of Health, National Institute of Allergy \\ and Infectious Diseases, Bethesda, Maryland 20892-0460 USA
}

The mammalian Daxx gene has been identified in a diverse set of yeast interaction trap experiments. Although a facilitating role for Daxx in Fas-induced apoptosis has been suggested, Daxx's physiologic function remains unknown. To elucidate the in vivo role of Daxx, we have generated Daxx-deficient mice. Surprisingly, rather than a hyperproliferative disorder expected from the loss of a pro-apoptotic gene, mutation of Daxx results in extensive apoptosis and embryonic lethality. These findings argue against a role for Daxx in promoting Fas-induced cell death and suggest that Daxx either directly or indirectly suppresses apoptosis in the early embryo.

Received May 6, 1999; revised version accepted June 16, 1999.

Daxx is a $120-\mathrm{kD}$ protein that has been identified in several yeast interaction trap systems using a variety of different "baits" (Kiriakidou et al. 1997; Yang et al. 1997; Pluta et al. 1998). Because this set of interacting proteins appears so diverse, it has been difficult to evaluate the physiologic significance of these interactions. The highly conserved Daxx gene has a ubiquitous expression pattern (Kiriakidou et al. 1997; Yang et al. 1997) and is not a member of any previously identified families of proteins. Given the variety of observed interactions, including a novel one described here, the functional significance of these and, hence, the physiologic role of Daxx remains in doubt.

Daxx was first reported as a protein that associates with the intracellular domain of Fas in an interaction trap system in yeast (Yang et al. 1997). Furthermore, Yang et al. demonstrated that Daxx enhanced Fas-mediated apoptosis when the two proteins were coordinately overexpressed. They also showed that this apoptosis was dependent on the Jun amino-terminal kinase (JNK) pathway. Specifically, Daxx was shown to function by activating the JNK kinase kinase, ASK1, in cotransfection assays (Chang et al. 1998). Previously, Fas was shown to

[Key Words: Daxx; yeast two-hybrid; apoptosis; Fas]

${ }^{5}$ Corresponding author.

E-MAIL Leder@rascal.med.harvard.edu; FAX (617) 432-7944. bind FADD (Mort 1) via its cytoplasmic domain (Boldin et al. 1995; Chinnaiyan et al. 1995) and activate procaspase-8 (Boldin et al. 1996; Muzio et al. 1996), thereby initiating the caspase cascade. Interestingly, cells deficient in FADD or caspase-8 are resistant to death induction through Fas (Juo et al. 1998; Yeh et al. 1998; Zhang et al. 1998), implying that Daxx should not be sufficient for induction of apoptosis. Moreover, a cell line expressing a mutant version of Fas unable to bind FADD (Fas $\Delta$ ) is insensitive to the induction of apoptosis through Fas despite the ability of Fas $\Delta$ to bind Daxx (Chang et al. 1999|. Although Fas $\Delta$-expressing cells cannot undergo Fas-induced apoptosis, they nonetheless retain the ability to induce JNK activity (Chang et al. 1999).

Although its initial identification placed Daxx in the Fas pathway, Daxx has also been identified in additional interaction trap system studies using bait proteins that appear to be unrelated to Fas-induced apoptosis. For example, Kiriakidou et al. (1997) cloned monkey and human $D A X X$ in a search for transcription factors that regulate the promoter of the steroidogenic acute regulatory protein gene. An additional group identified Daxx as interacting with CENP-C, an intrinsic protein of the human centromere thought to be crucial for chromosome segregation and mitotic progression (Pluta et al. 1998). Our laboratory has now identified Daxx in association with yet another protein, DNA methyltransferase I.

To directly assess the significance of these various interactions and to learn the in vivo role of Daxx, we have used targeted disruption to create a null mutation of the mouse Daxx gene by homologous recombination in embryonic stem (ES) cells. Our results demonstrate that a deficiency in Daxx results in embryonic lethality by day 9.5 of gestation. Furthermore, in contrast to what might have been expected given the proposed role of Daxx in promoting apoptosis, this lethality is marked by significant apoptosis evident in Daxx-deficient embryos by day 7.5. Consistent with this, increased levels of apoptosis are also apparent in $\mathrm{Daxx}^{-/-}$cell lines. Our results thus indicate that Daxx is an essential gene in mouse development and plays a role-either directly or indirectlyin preventing apoptosis.

\section{Results and Discussion}

Targeted disruption of the Daxx gene results in embryonic lethality

Because of our long-standing interest in genetic imprinting, we came upon Daxx while using a yeast two-hybrid system to screen a HeLa cell library for proteins that interact with DNA methyltransferase I (data not shown). Because Daxx had been shown to interact in this system with several other proteins, we hoped to gain insight into its in vivo function by targeting the Daxx locus using homologous recombination.

Accordingly, the genomic locus of Daxx was cloned from a $129 / \mathrm{SV}$ female liver library and found to be 


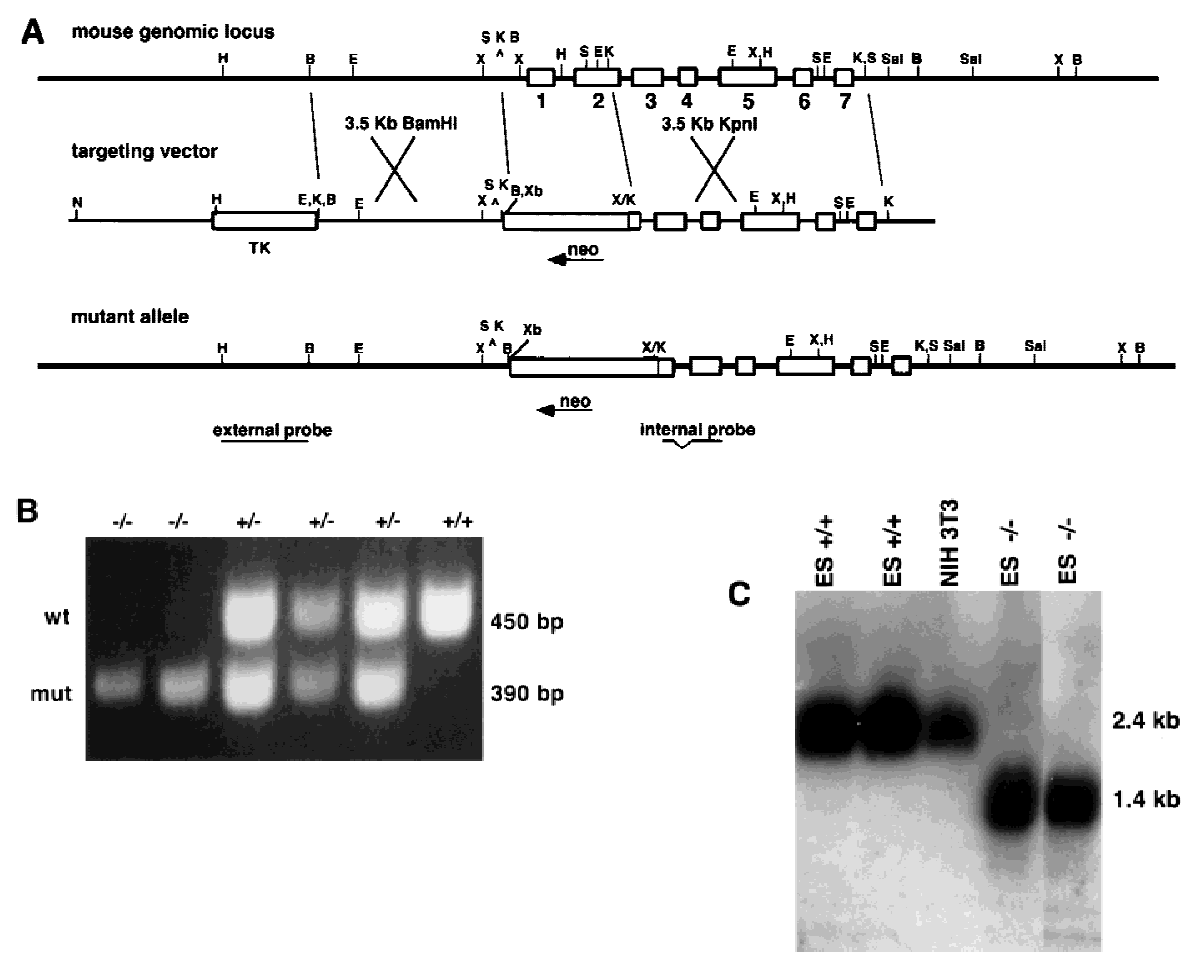

Figure 1. Targeted disruption of the mouse Daxx gene. (A) A map of the mouse genomic Daxx locus. The seven exons are indicated as open boxes. The targeting vector includes a thymidine kinase (TK) gene for negative selection and a neo gene for positive selection. Homologous recombination and insertion of neo results in a $2.5-\mathrm{kb}$ deletion including exon 1 and most of exon 2. The positions of an external probe from $5^{\prime}$ of Daxx and of an internal cDNA probe used for genotyping HindIII-digested DNA by Southern blot analysis are shown. (B) BamHI; (E) EcoRI; (H) HindIII; (K) KpnI; (S) SacI; (Sal) SalI; (X) XhoI; (Xb) XbaI. Not all $\mathrm{K}$ and $\mathrm{S}$ sites are shown. $(B)$ PCR analysis of embryo yolk sac genomic DNA. $(C)$ Northern blot analysis of total RNA from blastocyst-derived cell lines. A cDNA probe, generated by PCR and encompassing bp 1596-2274, detects a wild-type band of $2.4 \mathrm{~kb}$. In mutant cells, a stable transcript of $1.4 \mathrm{~kb}$ is detected.

composed of seven exons (Fig. 1A). This gene was localized to a position on mouse chromosome 17 within the MHC with the following gene order and recombinational distances: C-Pim1-4.4 $\pm 2.1-$ Daxx-1.1 \pm 1.1 Notch4-1.4 $\pm 1.4-\operatorname{Tnf}$. This region is homologous to human chromosome $6 \mathrm{p} 21.3$, to which the human DAXX gene has been mapped previously (Kiriakidou et al. 1997). A targeting construct was generated in the pPNT vector, whereby a neo ${ }^{\mathrm{R}}$ cassette in the reverse orientation replaced $2.5 \mathrm{~kb}$ of the Daxx locus, including exon I, intron I, and a major portion of exon II (Fig. 1A). Following transfection of the construct into TC1 ES cells (Deng et al. 1996) and selection in G418 and FIAU, 126 colonies were picked, 7 of which had undergone homologous recombination at the Daxx locus. Injection of a heterozygous ES clone into blastocysts resulted in the generation of germ-line-competent chimeras, which were subsequently bred with $129 / \mathrm{SvEv}$ mice. Genotypic analysis following mating of heterozygous mice revealed that of several hundred $\mathrm{F}_{2}$ generation progeny examined, none was homozygous for the Daxx mutation. Daxx heterozygous animals were present in expected ratios, and the heterozygotes appeared phenotypically normal. Based on these findings, we presumed that homozygous mutants were dying during embryonic development.

\section{Early lethality of Daxx mutants is characterized by extensive apoptosis}

To establish the developmental stage at which Daxx homozygous embryos die, genotypic analyses of timed matings were performed. A PCR assay was employed for genotyping the embryos (Fig. 1B). As early as E9.5, no mutant embryos were detected, indicating that they were dying prior to this stage. Mutant embryos were evident at E8.5, although in lower than expected ratios. In an attempt to suppress or at least ameliorate the lethal phenotype, the Daxx mutation was crossed onto an outbred background by breeding Daxx heterozygotes (129/SvEv) with Black Swiss (BLKSW) mice. Outbred homozygous mutant embryos were identified at E9.5, although not later, demonstrating a slightly increased viability on the outbred background. Except as noted otherwise, further studies of mutant embryos were performed on outbred crosses.

Morphologic analysis of whole embryos revealed that early in development, mutant embryos are readily distinguishable from their wild-type and heterozygous counterparts. At E7.5, the mutant embryos are significantly smaller and highly disorganized (data not shown). By E8.5 and E9.5 the decreased size and extensive disorganization of the mutant relative to the wild-type embryos is dramatic (Fig. 2A). At these later stages, it is possible to distinguish mutants from their littermates based on the smaller size of the deciduae (Fig. 2B).

Histologic analysis was performed to further characterize the mutant embryos. Paraffin-embedded fixed sections derived from E7.5 and E8.5 embryos were examined following staining with hematoxylin and eosin. At E7.5, mutant embryos are markedly reduced in size and highly disorganized as compared to wild-type and heterozygous littermates (Fig. 2C). In the mutant embryo, the ectoderm-derived cells fail to organize as a uniform layer but, rather, remain as a clump of cells; in a heterozygous littermate, formation of the neuroepithelium is evident. By E8.5, specific tissues and organs of wild-type embryos are distinguishable, including the neural tube, somites, foregut, branchial arches, myocardium, and primitive heart chambers (Fig. 2D). In contrast, the mutant embryos lack somite formation and fail to develop 

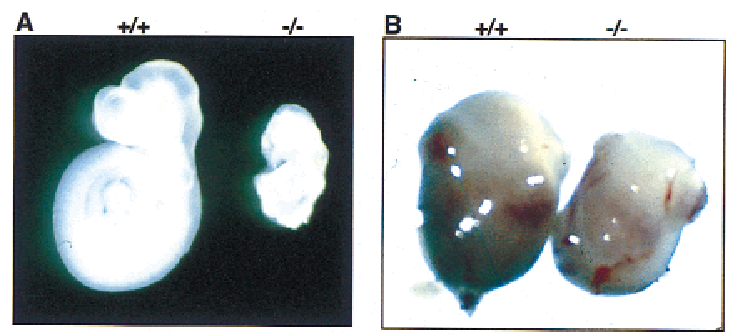

C
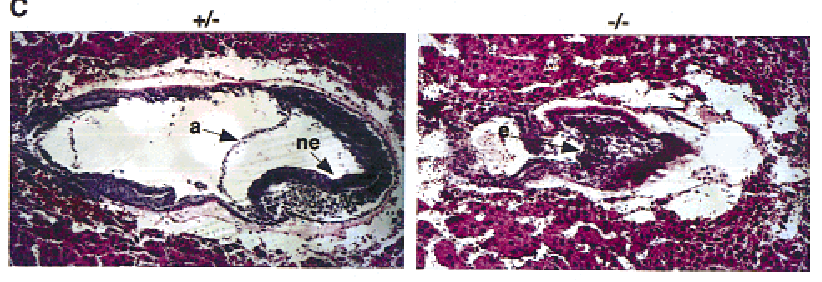

D
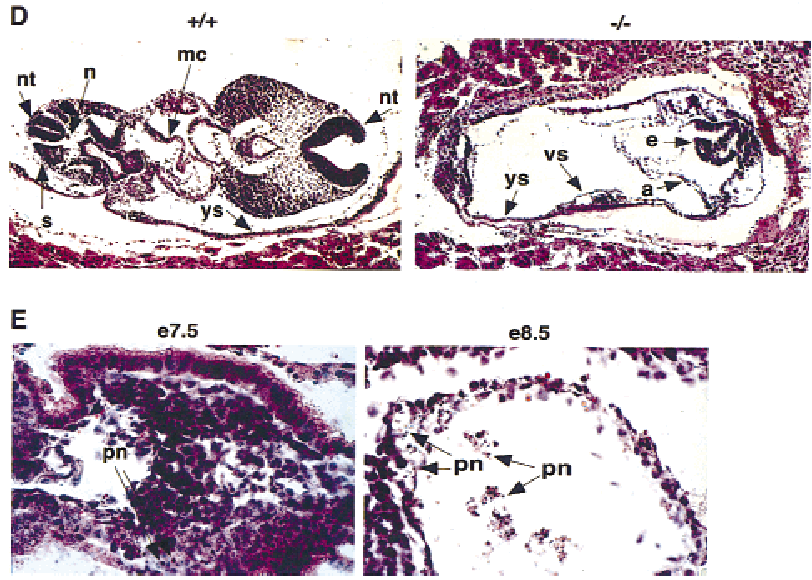

Figure 2. Daxx mutant embryos are growth retarded, highly disorganized, and undergo extensive apoptosis. (A) A pair of E9.5 wild-type and Daxx mutant littermates are compared. (B) A pair of E9.5 wild-type and mutant deciduae are compared. $(C-E)$ Hematoxylin and eosin-stained paraffin-embedded sections of embryos from E7.5 +/- and -/- littermates $(C)$ and E8.5 + /+ and -/- littermates $(D)$. (a) Amnion; (e) epiblast; $(\mathrm{mc})$ myocardium; (ne) neuroepithelium; (n) notochord; (nt) neural tube; (s) somites; (vs) vascular space; (ys) yolk sac. (E) Evidence of pyknotic nuclei (pn) in sections from -/- embryos at E7.5 and E8.5.

specific tissue types or organs (Fig. 2D). There is also no evidence for formation of the placenta in the mutant embryos, although extraembryonic structures such as the yolk sac and amnion are apparent in the mutants. In addition, the mutant embryos do exhibit some primitive fetal blood formation.

Histologic examination of E7.5 mutant embryos revealed the presence of pyknotic nuclei characterized by condensed chromatin, providing morphologic evidence for apoptosis in the early embryos (Fig. 2E). By E8.5, the presence of pyknotic nuclei throughout the embryo is suggestive of global apoptosis (Fig. 2E). To confirm the presence of apoptosis in the mutant embryos, end-labeling of nucleosome fragments with digoxigenin-UTP by the TUNEL assay was performed. Relative to wild-type littermates, mutant embryos at E7.5 showed signifi- cantly increased levels of apoptosis (Fig. 3A). At E8.5, the high levels of apoptosis were particularly striking in the allantois as well as in the head and tail regions of the neuroepithelium (Fig. 3B,C). There was also evidence of apoptosis in the population of fetal hematopoietic cells (Fig. 3C). Together, these data suggest that disruption of the Daxx locus results in extensive apoptosis during embryogenesis.

\section{$\mathrm{Daxx}^{-/-}$cell lines exhibit increased levels of apoptosis}

Given the early lethality of the Daxx embryos, derivation of - / - cell lines was essential for further study of the mutation. Because of the severity and early lethality of the phenotype, such lines could not be derived from embryonic fibroblasts. Instead, ES cell lines were established by culturing the inner cell mass of blastocysts derived from matings of heterozygous 129/SvEv mice. Of 26 cell lines established, 3 were homozygous mutant at the Daxx locus, as determined by Southern blot analysis (data not shown). To confirm that the mutant cell lines were not expressing the wild-type Daxx transcript, Northern blot analysis was performed on a panel of wildtype and mutant cell lines. No wild-type transcript $(2.4$ $\mathrm{kb}$ ) was present in the $-/$ - cell lines (Fig. 1C). In mutant
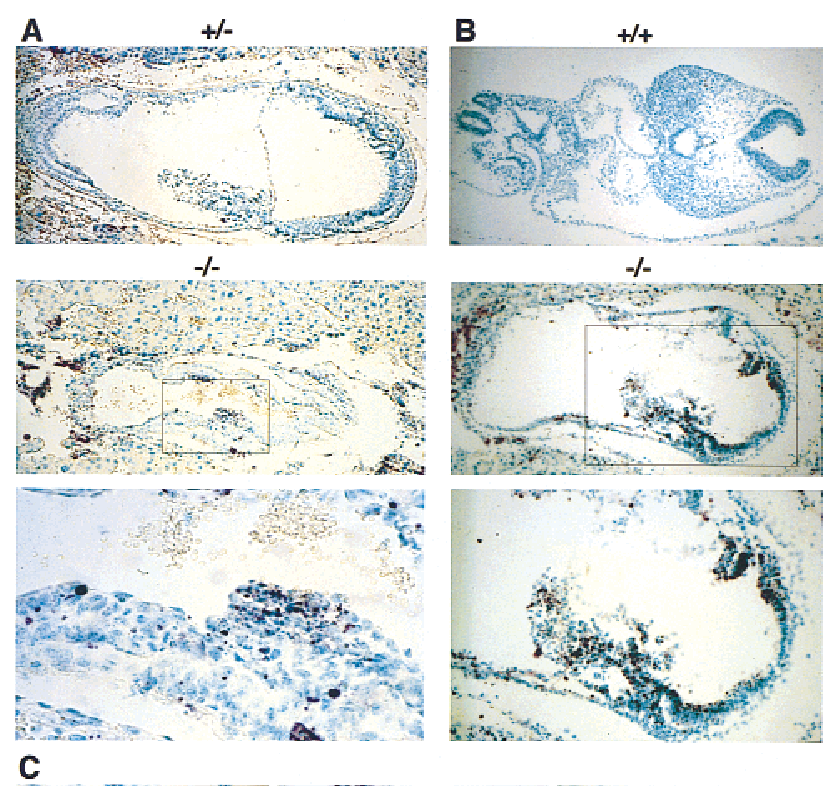

$-1=$
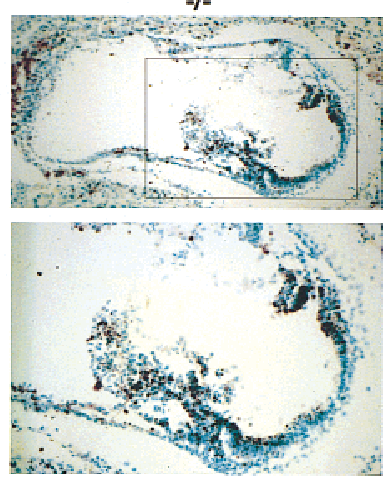

C

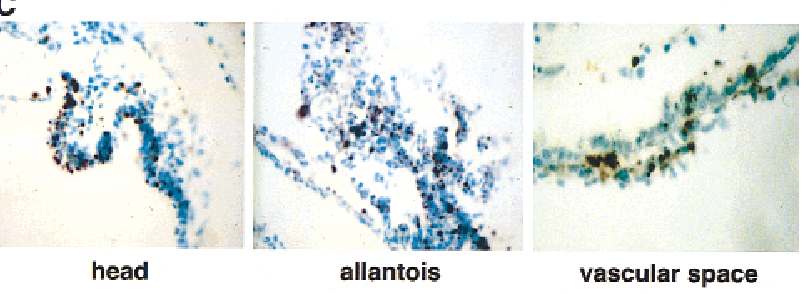

Figure 3. Extensive apoptosis in Daxx mutant embryos. TUNEL assay by digoxigenin-UTP end-labeling of nucleosome fragments of paraffin-embedded sections from E7.5 + / - and -/littermates $(A)$; E8.5 +/+ and -/- littermates $(B)$; the head region, allantois, and vascular space of E8.5 -/- embryos $(C)$. 


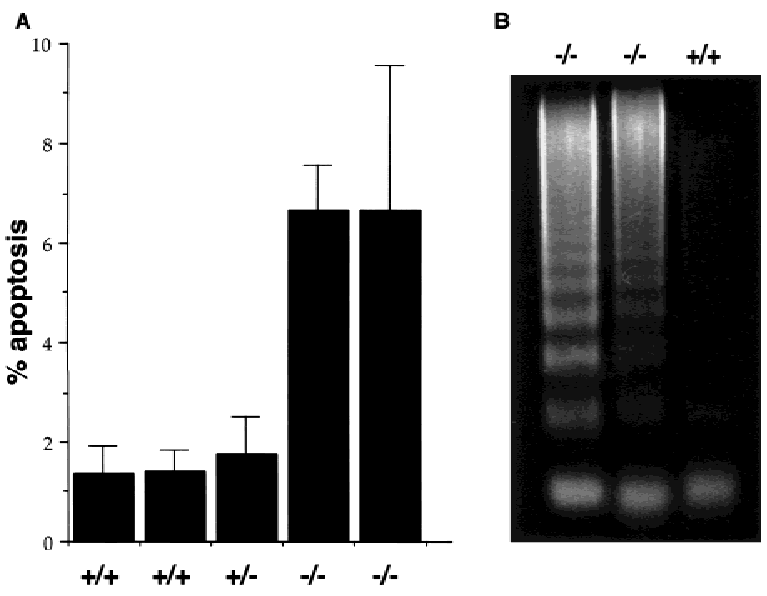

Figure 4. Increased levels of apoptosis in Daxx-deficient cell lines. (A) The percentage of apoptotic cells in wild-type and mutant cell cultures was measured as the sub- $\mathrm{G}_{1}$ peak following propidium iodide staining and FACS analysis. Each bar represents an independent cell line. Error bars indicate s.D. $(B)$ A DNA fragmentation assay was performed by isolating low-molecular-weight DNA from $1 \times 10^{7}$ wild-type or mutant cells, followed by separation on a $2 \%$ agarose gel and staining with ethidium bromide. Each lane represents an independent cell line.

cell lines, the wild-type transcript is replaced by a mutant form that migrates at $1.4 \mathrm{~kb}$ (Fig. 1C). Homozygous mutant as well as heterozygous embryos were also found to express this mutant transcript (data not shown). Given the appearance of this transcript in heterozygotes, which are phenotypically normal, it is unlikely that the transcript represents a dominant negative version of Daxx.

Because extensive apoptosis was observed in Daxx mutant embryos, we were interested in evaluating $\mathrm{Daxx}^{-/-}$cell lines for evidence of increased apoptosis. To assess the levels of cell death, wild-type and mutant cells were fixed, stained with propidium iodide, and subsequently subjected to FACS analysis. A sub-G Geak, $_{1}$, comprised of apoptotic cells, was enhanced severalfold in $\mathrm{Daxx}^{-/-}$relative to $\mathrm{Daxx}^{+/+}$or $\mathrm{Daxx}^{+/-}$cell lines (Fig. 4A). FACS analysis following staining with acridine orange revealed a similar increase in the apoptotic population in mutant versus wild-type cells (data not shown). Following serum starvation of wild-type and mutant cell lines, a proportional increase in the apoptotic fraction was observed in all cell lines (data not shown). A DNA fragmentation assay was employed as an additional measure of apoptosis in the cell lines. As shown in Figure 4B, a DNA laddering effect was evident in the $\mathrm{Daxx}^{-/-}$cell lines to a greater extent than in wild-type cells.

The observed apoptosis in Daxx-deficient embryos, which is mimicked in cell lines lacking Daxx, is in contrast to the anticipated phenotype, namely increased cell survival, were Daxx to play a direct role in Fas-mediated apoptosis. Targeted disruption of FADD, for example, results in embryonic lethality, characterized by cardiac defects and accumulation of erythrocytes (Yeh et al. 1998; Zhang et al. 1998), likely because of a lack of death induction of this particular cell population. The absence of caspase- 8 leads to a comparable phenotype (Varfolomeev et al. 1998). Similarly, mutation of Fas, while not lethal, results in massive production of lymphocytes and liver hyperplasia (Adachi et al. 1995, 1996).

Our findings suggest that Daxx plays an opposite role such that it prevents apoptosis. However, our data do not distinguish between apoptosis being a direct effect of the absence of Daxx and a secondary result of the Daxx mutation. Thus, Daxx may possibly prevent apoptosis by means of its involvement in a related process, such as DNA damage or repair. Mutation in the recombinatorial repair gene rad51 (Lim and Hasty 1996), for example, results in embryonic lethality at about the same stage as Daxx and is characterized by increased apoptosis. Similarly, a mutation in the gene encoding Bloom's helicase (Chester et al. 1998) results in significant levels of apoptosis and embryonic lethality, albeit at a slightly later stage in development.

\section{A role for Daxx in the nucleus}

Having initially identified Daxx from a yeast two-hybrid screen using DNA methyltransferase I as bait, we expected that Daxx would be a nuclear protein. To address this, we prepared an affinity-purified polyclonal antibody $(\alpha$-Daxx $)$, the specificity of which was confirmed by the presence of a 120-kD Daxx band in extracts derived from wild-type ES cell lines that is absent in Daxx-deficient cell lines (Fig. 5A). Because the $\alpha$-Daxx antibody also recognized a nonspecific lower molecular weight band
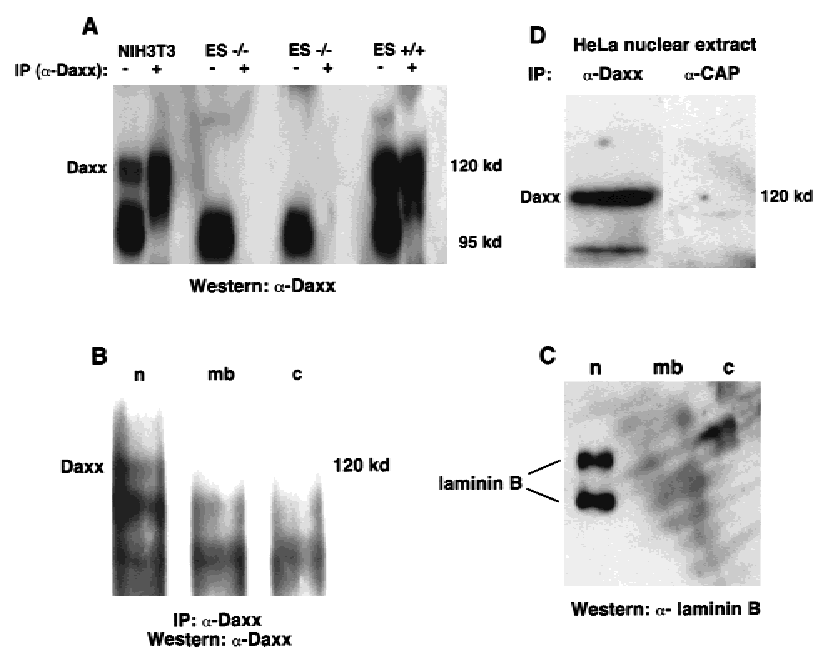

Figure 5. Daxx is localized to the nucleus. (A) Total cell extracts were prepared from wild-type and Daxx-deficient cell lines. Total cell lysate $(30 \mu \mathrm{g})$ or cell lysate that had been immunoprecipitated with $\alpha$-Daxx $(1.5 \mathrm{mg})$, was loaded on an $8 \%$ SDS-polyacrylamide gel. $\alpha$-Daxx was used for immunoblotting. $(B)$ Wild-type ES cells were fractionated into the following subcellular components: nucleus $(\mathrm{n})$; membrane $(\mathrm{mb})$; and cytosol (c). Immunoprecipitation and immunoblotting were performed with $\alpha$-Daxx. $(C)$ HeLa nuclear extracts were used for immunoprecipitation with $\alpha$-Daxx or $\alpha$-CAP. $\alpha$-Daxx was used for immunoblotting. $(D)$ Immunoblotting of subcellular fractions was performed with an antibody recognizing laminin B. 
(Fig. 5A), it was not suitable for use in immunofluorescence experiments.

To determine the subcellular localization of Daxx, wild-type ES cells were fractionated and subsequently immunoprecipitated with $\alpha$-Daxx. Western blot analysis with $\alpha$-Daxx revealed the presence of Daxx exclusively in the nuclear fraction (Fig. 5B). As a control for the fractionation procedure, laminin B was shown to be present in the nuclear fraction as expected (Fig. 5D). Confirming its presence in the nucleus, Western blot analysis detected Daxx in HeLa nuclear extracts following immunoprecipitation with $\alpha$-Daxx but not with an irrelevant antibody (Fig. 5C).

Our findings support a role for Daxx in the nucleus of the cell. Pluta et al. (1998) have also provided evidence suggesting that Daxx may be a nuclear protein, potentially localized to centromeres during interphase (Kiriakidou et al. 1997). The presence of Daxx in the nucleus was consistent with our having initially identified Daxx as interacting with DNA methyltransferase I. Moreover, like Daxx, targeted disruption of the DNA methyltransferase I gene results in early lethality in the mouse (Li et al. 1992; Lei et al. 1996). However, using a number of different approaches, we have found that Daxx mutant embryos and cell lines appear to have no defects with respect to either global or gene-specific methylation (data not shown). It is possible that the association of Daxx with methylation is secondary to its essential role in the mouse and/or that there is redundancy among methylase-associated proteins such as Daxx. Alternatively, given that Daxx has now been identified in multiple yeast interaction trap screens with a variety of baits, it is likely that in many of these instances the identification of Daxx may represent a false positive in the screen.

If Daxx were to physiologically interact with the cytoplasmic domain of Fas, a membrane-bound molecule, it should be located in the cytoplasm. In contrast, we show that Daxx is a nuclear and not a cytoplasmic protein. Our findings may be reconciled with previous data suggesting a role for Daxx in the induction of Fas-mediated cell death by recognizing that the high levels of overexpression in such experiments might not reflect the physiologic activities of the involved proteins. Alternatively, the effect observed on JNK activation and attributed to Daxx may be indirect. Finally, the ability of Fas $\Delta$-expressing cells to activate JNK may be a function of signaling through molecules other than Daxx. Our data now provide in vivo evidence demonstrating that Daxx has an essential role in the mouse and likely protects from apoptosis at early stages of development.

\section{Materials and methods}

Construction of a targeting vector and generation of germ-line chimeras

The 3 '-flanking genomic segment used for the targeting construct was a 3.5-kb KpnI fragment. Following treatment with T4 DNA polymerase to create a blunt end, the fragment was cloned into pPNT (Tybulewicz et al. 1991) that had been digested with XhoI and subsequently treated with the Klenow enzyme. The 5'-flanking segment, a 3.5-kb BamHI fragment, was inserted into the BamHI site of pPNT. The targeting construct was linearized with NotI and transfected into TC1 129/SvEv ES cells (Deng et al. 1996). Selection and picking of G418 and FIAU-resistant colonies was essentially as described (Deng et al. 1994). Southern blot analysis revealed that 7 of 126 clones had undergone homologous recombination at the Daxx locus. Cells from clone 17 were microinjected into C57BL/J6 blastocysts followed by transfer into pseudopregnant Swiss Webster (Taconic) foster mothers. Resulting high-grade agouti chimeras were mated to 129 /SvEv females. Germ-line transmission of the targeted Daxx allele was predicted by the agouti coat color in the $F_{1}$ offspring and confirmed by Southern blot analysis.

Chromosomal localization of mouse Daxx

The Daxx gene was chromosomally mapped using a Sall fragment from the region immediately downstream of Daxx (see Fig. 1A). On Southern blots this probe identified Pst Iragments of $2.5 \mathrm{~kb}$ in Mus spretus and C58/J mice and $2.1 \mathrm{~kb}$ in NFS/N. Inheritance of these fragments was followed in the genetic cross (NFS $/ \mathrm{N} \times$ M. spretus) $\times$ M. spretus or C58/J (Adamson et al. 1991). Genes were ordered by minimizing the number of recombinants.

PCR analysis

Genotyping of E7.5-E10.5 embryos was performed on genomic DNA derived from yolk sacs. Genotyping of hematoxylin and eosin-stained sections was performed as described previously (Zeitlin et al. 1995). For all PCR reactions, three primers were added simultaneously. Primer $F_{1}$ (GTGTACATTAACGAGCTCTGC) corresponds to bp 448-468 of mouse Daxx (sense orientation), a region of exon 2 subject to targeted deletion. Primer R2 (TTCTCCACGGCTCTCAGCAC) corresponds to bp 959-940 (antisense orientation) of Daxx, from the 3' end of exon 2, which is retained at the targeted allele. Primer PNT (GCGAAGGAGCAAAGCTGCTAT) is derived from the $5^{\prime}$ end of neo and is in the antisense orientation. PCR reactions were performed with Taq polymerase (Boehringer Mannheim) under the following conditions: denaturation at $95^{\circ} \mathrm{C}$ for $5 \mathrm{~min}$, followed by 30 cycles of $94^{\circ} \mathrm{C}$ for $20 \mathrm{sec}, 60^{\circ} \mathrm{C}$ for $30 \mathrm{sec}$, and $72^{\circ} \mathrm{C}$ for $1 \mathrm{~min}$. Reaction products were electrophoresed on $2 \%$ agarose gels.

Northern blot analysis

Total RNA was isolated from NIH-3T3 cells, wild-type ES cells or -/ - ES cells using RNA STAT-60 (Tel-Test). ES cells were grown three or more generations off feeder layers to prevent feeder cell RNA contamination. Twenty-three micrograms of RNA was electrophoresed on a $1 \%$ formaldehyde agarose gel and transferred to Genescreen nylon membrane (NEN Life Science Products). The blot was hybridized with a ${ }^{32} \mathrm{P}$-labeled (NEN) random-primed (Stratagene) probe, washed, and exposed to film for 5 days.

Embryo histology and TUNEL assay

Whole embryos were fixed in $4 \%$ paraformaldehyde and subsequently embedded in paraffin. Embryo sections of $7-\mu \mathrm{m}$ thickness were stained with hematoxylin and eosin. TUNEL assay was performed on embryo sections using Apotags (Intergen).

Cell death analysis

ES cells, grown two generations off feeder layers to prevent feeder cell contamination, were fixed in $70 \%$ ethanol. Low-molecular-weight DNA was extracted at $37^{\circ} \mathrm{C}$ as described (Ausubel et al. 1990). Samples were incubated with RNase A $(0.5 \mathrm{mg} / \mathrm{ml})$ and propidium iodide $(50 \mu \mathrm{g} / \mathrm{ml})$, followed by analysis on a FACS Calibur flow cytometer (Becton-Dickinson).

For DNA fragmentation assay, low-molecular-weight DNA was extracted from $1 \times 10^{7}$ cells, as described (Grimm and Leder 1997).

Subcellular fractionation, immunoprecipitation, and Western blotting Subcellular fractionation of wild-type ES cells was essentially as described (Chan and Leder 1996). Immunoprecipitations were performed using protein A-coupled Sepharose beads (Pierce). Antibodies were raised (Covance) against an amino-terminal GST fusion protein of Daxx (amino acids 1-440), and the final bleed was subsequently affinity purified against amino acids 1-440 of Daxx, which was covalently bound to cyanogen bromide-activated Sepharose (Pharmacia Biotech). For Western blots, the affinity-purified $\alpha$-Daxx antibody was diluted 1:500. $\alpha$-Laminin B antibody was used at a dilution of 1:2000. 


\section{Acknowledgments}

We thank Cathie Daugherty O'Hara and Anne Harrington for their technical support in generating the Daxx knockout, Juanita Campos-Torres for her assistance with the FACS analysis, and David Conner's helpful advice regarding derivation of ES cells from blastocysts. We are also grateful to Nick Chester, Mark Bedford, and Yasumasa Ishida for their valuable guidance and for critical reading of this manuscript.

The publication costs of this article were defrayed in part by payment of page charges. This article must therefore be hereby marked 'advertisement' in accordance with 18 USC section 1734 solely to indicate this fact.

\section{References}

Adachi, M., S. Suematsu, T. Kondo, J. Ogasawara, T. Tanaka, N. Yoshida and S. Nagata. 1995. Targeted mutation in the Fas gene causes hyperplasia in peripheral lymphoid organs and liver. Nat. Genet. 11: 294-300.

Adachi, M., S. Suematsu, T. Suda, D. Watanabe, H. Fukuyama, J. Ogasawara, T. Tanaka, N. Yoshida, and S. Nagata. 1996. Enhanced and accelerated lymphoproliferation in Fas-null mice. Proc. Nat1. Acad. Sci. 93: 2131-2136.

Adamson, M.C., J. Silver, and C.A. Kozak. 1991. The mouse homolog of the Gibbon ape leukemia virus receptor: Genetic mapping and a possible receptor function in rodents. Virology 183: 778-781.

Ausubel, F.M., R. Brent, R.E. Kingston, D.D. Moore, J.G. Seidman, J.A. Smith, and K. Struhl. 1990. Current protocols in molecular biology. Green Publishing Associates/Wiley Interscience, New York, NY.

Boldin, M.P., E.E. Varfolomeev, Z. Pancer, I.L. Mett, J.H. Camonis, and D. Wallach. 1995. A novel protein that interacts with the death domain of Fas/APO1 contains a sequence motif related to the death domain. J. Biol. Chem. 270: 7795-7798.

Boldin, M.P., T.M. Goncharov, Y.V. Goltsev, and D. Wallach. 1996. Involvement of $\mathrm{MACH}$, a novel MORT1/FADD-interacting protease, in Fas/APO-1- and TNF receptor-induced cell death. Cell 85: 803815 .

Chan, D.C. and P. Leder. 1996. Genetic evidence that formins function within the nucleus. J. Biol. Chem. 271: 23472-23477.

Chang, H.Y., H. Nishitoh, X. Yang, H. Ichijo, and D. Baltimore. 1998. Activation of apoptosis signal-regulating kinase 1 (ASK1) by the adapter protein Daxx. Science 281: 1860-1863.

Chang, H.Y., X. Yang, and D. Baltimore. 1999. Dissecting Fas signaling with an altered-specificity death-domain mutant: Requirement of FADD binding for apoptosis but not Jun $\mathrm{N}$-terminal kinase activation. Proc. Natl. Acad. Sci. 96: 1252-1256.

Chester, N., F. Kuo, C. Kozak, C.D. O'Hara, and P. Leder. 1998. Stagespecific apoptosis, developmental delay, and embryonic lethality in mice homozygous for a targeted disruption in the murine Bloom's syndrome gene. Genes \& Dev. 12: 3382-3393.

Chinnaiyan, A.M., K. O'Rourke, M. Tewari, and V.M. Dixit. 1995 FADD, a novel death domain-containing protein, interacts with the death domain of Fas and initiates apoptosis. Cell 81: 505-512.

Deng, C., A. Wynshaw-Boris, M.M. Shen, C. Daugherty, D. Ornitz, and P. Leder. 1994. Murine FGFR-1 is required for early postimplantation growth and axial organization. Genes \& Dev. 8: 3045-3057.

Deng, C., A. Wynshaw-Boris, A. Kuo, F. Zhou, and P. Leder. 1996. Fibroblast growth receptor 3 is a negative regulator of bone growth. Cell 84: 911-921.

Grimm, S. and P. Leder. 1997. An apoptosis-inducing isoform of neu differentiation factor (NDF) identified using a novel screen for dominant, apoptosis-inducing genes. J. Exp. Med. 185: 1137-1142.

Juo, P., C.J. Kuo, J. Yuan, and J. Blenis. 1998. Essential requirement for caspase-8/FLICE in the initiation of the Fas-induced apoptotic cascade. Curr. Biol. 8: 1001-1008.

Kiriakidou, M., D.A. Driscoll, J.M. Lopez-Guisa, and J.F. Strauss III. 1997. Cloning and expression of primate Daxx cDNAs and mapping of the human gene to chromosome 6p21.3 in the MHC region. DNA Cell Biol. 16: 1289-1298.

Lei, H., S.P. Oh, M. Okano, R. Juttermann, K.A. Goss, R. Jaenisch, and E. Li. 1996. De novo DNA cytosine methyltransferase activities in mouse embryonic stem cells. Development 122: 3195-3205.

Li, E., T.H. Bestor, and R. Jaenisch. 1992. Targeted mutation of the DNA methyltransferase gene results in embryonic lethality. Cell 69: 915926.

Lim, D.S. and P. Hasty. 1996. A mutation in mouse rad51 results in an early embryonic lethal that is suppressed by a mutation in p53. Mol. Cell Biol. 16: 7133-7143.

Muzio, M., A.M. Chinnaiyan, F.C. Kischkel, K. O’Rourke, A. Shevchenko, J. Ni, C. Scaffidi, J.D. Bretz, M. Zhang, R. Gentz, M. Mann, P.H. Krammer, M.E. Peter, and V.M. Dixit. 1996. FLICE, a novel FADD-homologous ICE/CED-3-like protease, is recruited to the CD95 (Fas/APO-1) death-inducing signaling complex. Cell 85: 817-827.

Pluta, A.F., W.C. Earnshaw, and I.G. Goldberg. 1998. Interphase-specific association of intrinsic centromere protein CENP-C with HDaxx, a death domain-binding protein implicated in Fas-mediated cell death. J. Cell Sci. 111: 2029-2041.

Tybulewicz, V.L., C.E. Crawford, P.K. Jackson, R.T. Bronson, and R.C. Mulligan. 1991. Neonatal lethality and lymphopenia in mice with a homozygous disruption of the c-abl proto-oncogene. Cell 65: 11531163.

Varfolomeev, E.E., M. Schuchmann, V. Luria, N. Chiannilkulchai, J.S Beckmann, I.L. Mett, D. Rebrikov, V.M. Brodianski, O.C. Kemper, O. Kollet, T. Lapidot, D. Soffer, T. Sobe, K.B. Avraham, T. Goncharov, H. Holtmann, P. Lonai, and D. Wallach. 1998. Targeted disruption of the mouse caspase 8 gene ablates cell death induction by the TNF receptors, Fas/Apo1, and DR3 and is lethal prenatally. Immunity 9: $267-276$.

Yang, X., R. Khosravi-Far, H.Y. Chang, and D. Baltimore. 1997. Daxx, a novel Fas-binding protein that activates JNK and apoptosis. Cell 89: 1067-1076.

Yeh, W.C., J.L. Pompa, M.E. McCurrach, H.B. Shu, A.J. Elia, A. Shahinian, M. Ng, A. Wakeham, W. Khoo, K. Mitchell, W.S. El-Deiry, S.W. Lowe, D.V. Goeddel, and T.W. Mak. 1998. FADD: Essential for embryo development and signaling from some, but not all, inducers of apoptosis. Science 279: 1954-1958.

Zeitlin, S., J.-P. Liu, D.L. Chapman, V.E. Papaioannou, and A. Efstratiadis. 1995. Increased apoptosis and early embryoic lethality in mice nullizygous for the Huntington's disease gene homologue. Nat. Genet. 11: 155-163.

Zhang, J., D. Cado, A. Chen, N.H. Kabra, and A. Winoto. 1998. Fasmediated apoptosis and activation-induced T-cell proliferation are defective in mice lacking FADD/Mort1. Nature 392: 296-300. 


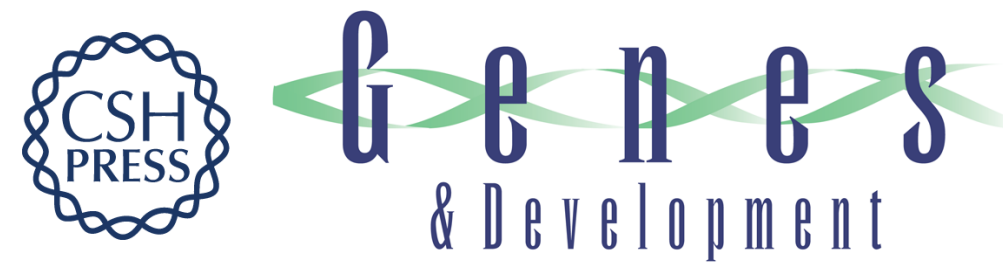

\section{Loss of Daxx, a promiscuously interacting protein, results in extensive apoptosis in early mouse development}

Jennifer S. Michaelson, Debra Bader, Frank Kuo, et al.

Genes Dev. 1999, 13:

References This article cites 26 articles, 12 of which can be accessed free at:

http://genesdev.cshlp.org/content/13/15/1918.full.html\#ref-list-1

License

Email Alerting Receive free email alerts when new articles cite this article - sign up in the box at the top Service right corner of the article or click here.

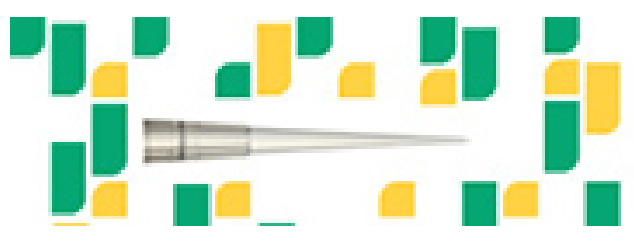

Focused on your science. 